Article

\title{
Enhancing the Mechanical Properties of Hot Roll Bonded Al/Ti Laminated Metal Composites (LMCs) by Pre-Rolling Diffusion Process
}

\author{
Cheng Zhang ${ }^{1}$, Shouxin Wang ${ }^{1}$, Hanxue Qiao ${ }^{1}$, Zejun Chen ${ }^{1,2, *(1)}$, Taiqian Mo ${ }^{1, *}$ and Qing Liu ${ }^{1}$ \\ 1 College of Materials Science and Engineering, Chongqing University, Chongqing 400044, China \\ 2 State Key Laboratory of Mechanical Transmission, Chongqing University, Chongqing 400044, China \\ * Correspondence: zjchen@cqu.edu.cn (Z.C.); mtq@cqu.edu.cn (T.M.); \\ Tel.: +86-23-65111547 (Z.C.); +86-151-2302-5115 (T.M.)
}

Received: 11 June 2019; Accepted: 16 July 2019; Published: 18 July 2019

\begin{abstract}
In this study, the traditional hot rolling to fabricate $\mathrm{Al} / \mathrm{Ti}$ laminated metal composites (LMCs) was improved by using a pre-rolling diffusion process. The effect of the pre-rolling diffusion on microstructure and mechanical properties of $\mathrm{Al} / \mathrm{Ti} \mathrm{LMC}$ s were investigated by various methods, such as optical microscope (OM), scanning electron microscope (SEM), energy dispersive spectrometer (EDS) and tensile tests. The results show that, with increasing diffusion temperature, the thickness in diffusion layer was increased and the mechanical properties of LMCs were improved obviously, which was attributed to the optimized interfacial structure after diffusion process. In addition, the formation of $\mathrm{TiAl}_{3}$ intermetallic compounds (IMCs) was detected in the bonding interface, which played an important role in improving the mechanical properties for $\mathrm{Al} / \mathrm{Ti} \mathrm{LMCs}$. The predicted results of stress-strain curves from rule of mixture (ROM) indicated that, there existed an extra interfacial strengthening in $\mathrm{Al} / \mathrm{Ti} \mathrm{LMC}$ s beside the mechanical properties provided by the contribution of constituent layers. The pre-rolling diffusion process is effective for the optimization of interfacial structure and improvement of mechanical properties in Al/Ti LMCs.
\end{abstract}

Keywords: laminated metal composites; pre-rolling; diffusion; mechanical properties; interface

\section{Introduction}

With the development of science and technology, the requirements of metal material have become diversified and a single traditional metal material is difficult to satisfy the needs of industry. Laminated metal composites (LMCs), which consists of two or more metals, have been paid a lot of attention due to their excellent performance in recent years [1]. Among these LMCs, Al/Ti composite was widely developed in aviation, aerospace, chemical equipment and transportation fields, which was attributed to the combination of the excellent performance between $\mathrm{Al}$ (low specific gravity, good electrical and thermal conductivity) and Ti (better high-temperature properties, high strength). What's more, it reduces the amount of expensive $\mathrm{Ti}$ alloy and saves production cost through the using of $\mathrm{Al} / \mathrm{Ti}$ LMCs [2-6].

For LMCs, many researches were focused on the fabrication processing, microstructure and mechanical properties [7-9]. A number of plastic deformation processes have been applied to the fabrication of LMCs including roll bonding [10,11], diffusion bonding [12-14], explosive welding [14,15] and reaction hot pressing $[16,17]$. Among these methods, roll bonding was widely used in the fabrication of $\mathrm{Al} / \mathrm{Ti} \mathrm{LMCs}$ due to relatively simple equipment and processing. On the other hand, the roll bonding is easier to promote large-scale production than other methods. However, in order to achieve the superior bonding between constituent layers, a hot rolling with high rolling temperature must be 
applied in the fabrication of Al/Ti LMCs [18,19]. It has been demonstrated that the high temperature process of roll bonding will inevitably introduce hard and brittle oxides and other inclusions in the bonding interface of LMCs $[19,20]$. The oxides and inclusions caused by high temperature will result in the decreasing of mechanical properties, such as bonding strength and toughness, due to the deteriorative combination of constituent layers. Therefore, it is necessary to eliminate the effect of oxides or inclusions on the bonding interface in order to obtain a LMCs with excellent performance.

In this work, a novel fabrication method based on pre-rolling diffusion was developed to manufacture Al/Ti LMCs in order to avoid the effect of inclusions at high temperature. The effect of the diffusion temperature on the microstructure and mechanical properties of Al/Ti LMCs was investigated in detail.

\section{Experimental Materials and Procedures}

\subsection{Experimental Materials}

The raw materials utilized in this experiment were commercial purity AA1100 Al sheets with a thickness of $1.5 \mathrm{~mm}$ and commercial purity TA2 Ti alloy sheets with a thickness of $2 \mathrm{~mm}$. The raw materials were cut into $150 \mathrm{~mm} \times 80 \mathrm{~mm}$ pieces parallel to the rolling direction. The chemical compositions of each material are presented in Tables 1 and 2.

Table 1. Chemical compositions of commercial purity AA1100 Al sheets (wt \%).

\begin{tabular}{ccccc}
\hline $\mathbf{Z n}$ & $\mathbf{S i}$ & $\mathbf{F e}$ & $\mathbf{T i}$ & $\mathbf{A l}$ \\
\hline 0.01 & 0.6 & 0.2 & 0.02 & Balance \\
\hline
\end{tabular}

Table 2. Chemical compositions of commercial purity TA2 Ti Alloy sheets (wt \%).

\begin{tabular}{cccccc}
\hline $\mathbf{F e}$ & $\mathbf{C}$ & $\mathbf{N}$ & $\mathbf{H}$ & $\mathbf{O}$ & $\mathbf{T i}$ \\
\hline 0.3 & 0.1 & 0.05 & 0.015 & 0.25 & Balance \\
\hline
\end{tabular}

\subsection{Fabrication Process of Al/Ti LMCS}

The surface of AA1100 and TA2 sheets were treated by mechanical grinding and then repeatedly cleaned in absolute ethyl alcohol to remove oxides and contaminants before the fabrication process. After the surface preparation process, AA1100 and TA2 sheets were stacked in the alternative order of AA1100/TA2/AA1100 as a "sandwich" form with a total thickness of $5 \mathrm{~mm}$. The stacked sheets were riveted together at one end to avoid the slide during roll bonding process. The riveted sheets were divided into four groups, three of which were subjected to pre-rolling diffusion and then hot-rolling as experimental groups while the left group was only hot rolled as a contrast with the former three to explore the effect of pre-rolling diffusion. The whole fabrication process was shown in Figure 1.

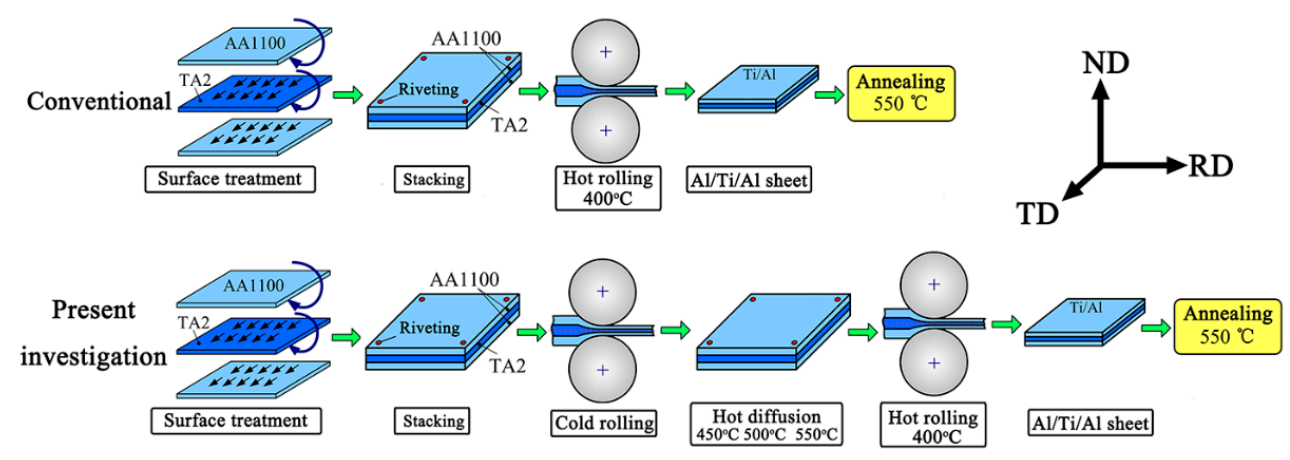

Figure 1. Schematic illustration showing the method for fabrication of $\mathrm{Al} / \mathrm{Ti}$ laminated metal composites (LMCs). 
In the comparison group (conventional fabrication process), the riveted sheets were preheated at $400{ }^{\circ} \mathrm{C}$ for $10 \mathrm{~min}$, and immediately rolled to get a reduction of $50 \%$ by one pass with $2.5 \mathrm{~mm}$ in thickness. The roll process was carried by a laboratory two-roll mill with rolls diameter of $170 \mathrm{~mm}$, rolling speed of $0.2 \mathrm{~m} / \mathrm{s}$ and maximum rolling force of $30 \mathrm{t}$. In the experimental groups, the LMCs were fabricated by two steps. In the first step, the riveted sheets were cold-rolled in a rolling reduction of $20 \%$, and then diffused at 450,500 and $550{ }^{\circ} \mathrm{C}$ for $1 \mathrm{~h}$, respectively. In the second step, the sheets were rolled at $400{ }^{\circ} \mathrm{C}$ to $2.5 \mathrm{~mm}$ in thickness by one pass in order to contrast with the comparison group. The diffusion sheets were denoted as D450, D500 and D550 to distinguish from each other. $\mathrm{The} \mathrm{Al} / \mathrm{Ti} \mathrm{LMCs}$ were annealed at $550{ }^{\circ} \mathrm{C}$ for $1 \mathrm{~h}$ to eliminate the internal stress and investigate the effect of annealing on mechanical properties. The heat treatment experiments were carried out in a vacuum environment.

\subsection{Characterization of Microstructure and Mechanical Properties}

The microstructure and interface structure of LMCs was characterized by optical microscope (OM, Axiovert 40 MAT, Zeiss, Oberkochen, Germany) and scanning electron microscope (SEM, VEGA3 LMH, Tescan, Brno, Czech Republic). The energy dispersive spectrometer (EDS, VEGA3 LMH, Tescan, Brno, Czech Republic) was conducted to analyze element diffusion in the bonding interface of LMCs at $5 \mathrm{kV}$ with a working distance of about $15 \mathrm{~mm}$. The mechanical properties of LMCs under different fabricated conditions were investigated. The tensile tests were performed at room temperature on the testing machine (AG-X, Shimadzu, Kyoto, Japan). The gauge section of the tensile specimen was $15 \mathrm{~mm}$ in length and $7 \mathrm{~mm}$ in width. A strain rate of $1.1 \times 10^{-3} \mathrm{~s}^{-1}$ was carried out in the tensile test. The shear test was conducted to evaluate the bonding strength of LMCs, and tested specimens were cut into the shape with a $35 \mathrm{~mm}$ in length and $7 \mathrm{~mm}$ in width. The tensile and shear test specimens are schematically shown in Figure 2.
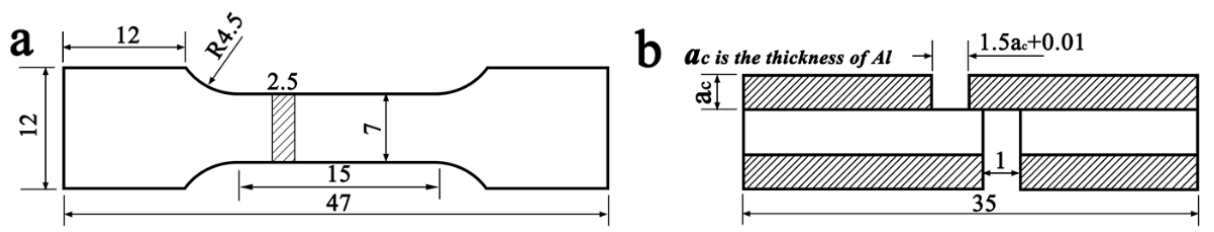

Figure 2. The schematic draw of specimens for (a) tensile and (b) shear test. (Unit: $\mathrm{mm}$ ).

\section{Results and Discussion}

\subsection{Microstructure after Pre-Rolling Diffusion Process}

Figure 3 shows the SEM images and corresponding EDS results in the bonding interface of Al/Ti LMCs diffused at 450,500 and $550{ }^{\circ} \mathrm{C}$. According to the SEM images, a clear interface can be detected, indicating the superior bonding in the layer interfaces was achieved. It is interesting to note that, the $\mathrm{Al}$ layers are embedded by Ti component with a zigzag shape, which is attributed to the effect of uncoordinate deformation between constituent layers. In addition, few oxides or inclusions can be found in the interfaces along rolling direction (RD) as a result of pre-rolling diffusion process (Figure 3a-c).

According to EDS results for the evolution of $\mathrm{Al}$ and Ti elements across the bonding interface, it can be deduced that a diffusion layer was formed in the bonding interface of LMCs under high temperature process (Figure $3 \mathrm{~d}-\mathrm{f}$ ). The thickness in diffusion layer was obtained from the element line scan and SEM image. As can be seen in Figure 3d-f, the thickness in diffusion layer of D450, D500 and D550 are 2.2, 3.2 and $4.6 \mu \mathrm{m}$, respectively. That is to say, the thickness in diffusion layer was increased with increasing pre-rolling diffusion temperature. Similar effect of temperature on bonding interface of Al/Ti LMCs was also reported previously [16]. 

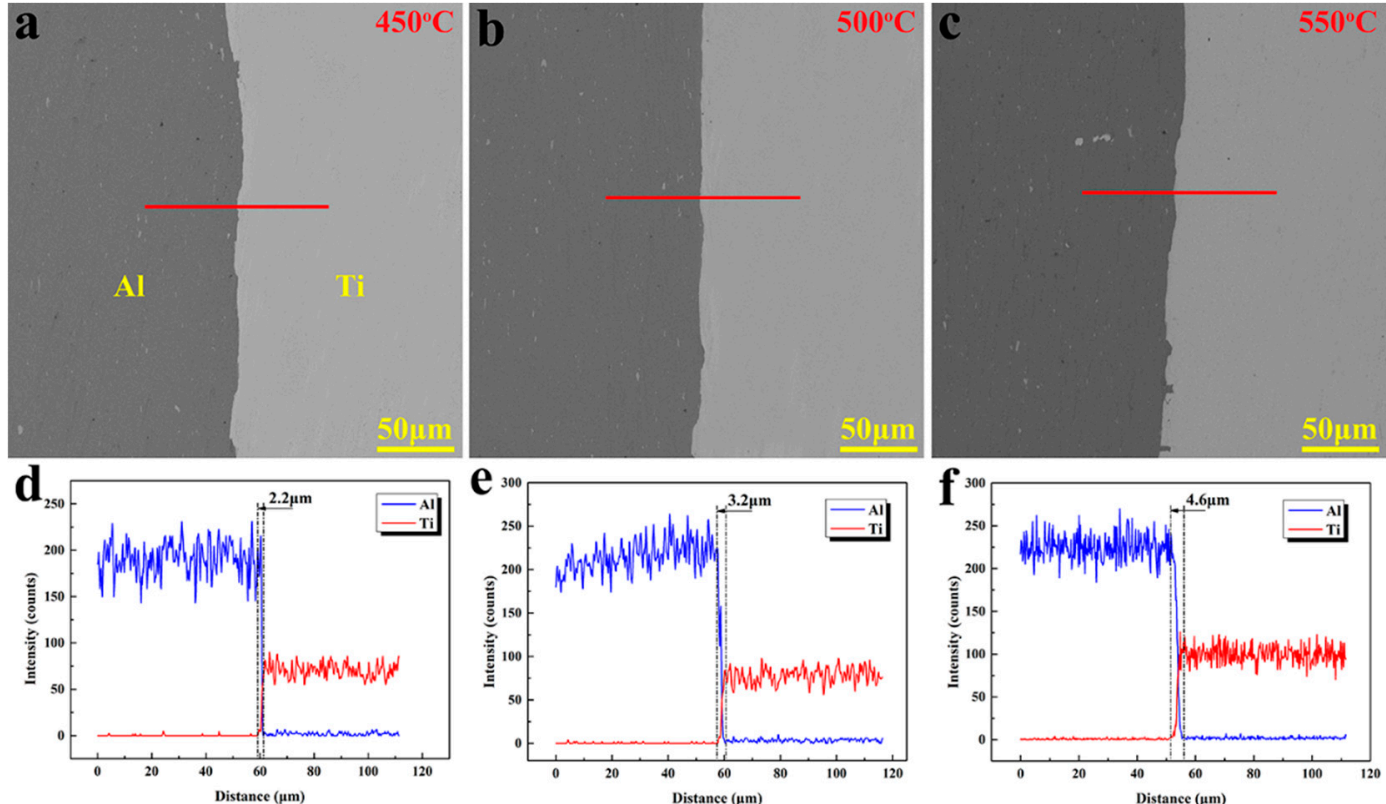

Figure 3. SEM image and element line scan in the bonding interface of $\mathrm{Al} / \mathrm{Ti} \mathrm{LMCs}$ after diffusion process: (a,d) $450{ }^{\circ} \mathrm{C}$; (b,e) $500{ }^{\circ} \mathrm{C}$; (c,f) $550{ }^{\circ} \mathrm{C}$.

Figure 4 illustrates the close-up view of element face scan in the bonding interface of LMCs diffused at $550{ }^{\circ} \mathrm{C}$ for $1 \mathrm{~h}$. A well-defined diffusion layer was formed in the bonding interface of Ti/Al LMCs as shown in Figure 4, which is consistent with the observation of Figure 3. It can be concluded that the formation of diffusion layer in the bonding interface will result in the oxygen induced by high temperature was limited. In addition, the table of Figure 4 shows that the percentage of $\mathrm{Al}$ and Ti atoms in the diffusion layer is approximately $74.34 \%$ and $25.66 \%$, respectively. The ratio of the two elements is nearly 3:1, according with the type of $\mathrm{IMCs} \mathrm{TiAl}_{3}$. Based on the Ti-Al binary phase diagram, the solubility of $\mathrm{Al}$ in the Ti matrix is greater than $10 \%$ in the temperature of $550{ }^{\circ} \mathrm{C}$ and the solubility of $\mathrm{Ti}$ in the $\mathrm{Al}$ matrix is almost zero. Besides, the free energy of $\mathrm{TiAl}_{3}$ is lowest among the main five Ti-Al IMCs $\left(\mathrm{Ti}_{3} \mathrm{Al}, \mathrm{TiAl}, \mathrm{TiAl}_{3}, \mathrm{TiAl}_{2}\right.$ and $\left.\mathrm{Ti}_{2} \mathrm{Al}_{5}\right)$ [21,22]. Therefore, when the solubility of $\mathrm{Al}$ atoms in the Ti matrix reaches a super saturation concentration, the nucleation requirements of $\mathrm{TiAl}_{3}$ phase will be achieved firstly. As is well known, $\mathrm{TiAl}_{3}$ is an ideal lightweight high-temperature structural phase with low density, high specific strength and high temperature resistance [21]. Thus the emergence of $\mathrm{TiAl}_{3}$ phase has an important effect on the mechanical properties of LMCs. In present study, the amount of $\mathrm{TiAl}_{3}$ phase increases with the diffusion temperature rising, which contributed to significant inhibition effect of oxide and contaminants in the interfaces.

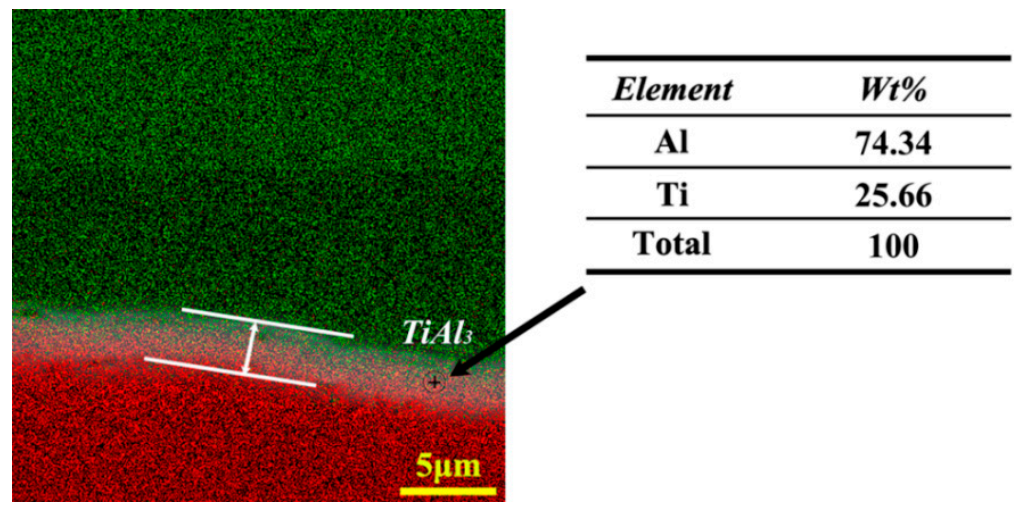

Figure 4. The element face scan in the bonding interface of LMCs diffused at $550{ }^{\circ} \mathrm{C}$ and the percentage of two elements at diffusion layer. 
Figure 5 shows the OM micrographs of $\mathrm{Al}$ layer and Ti layer of LMCs undergoing pre-rolling diffusion process.
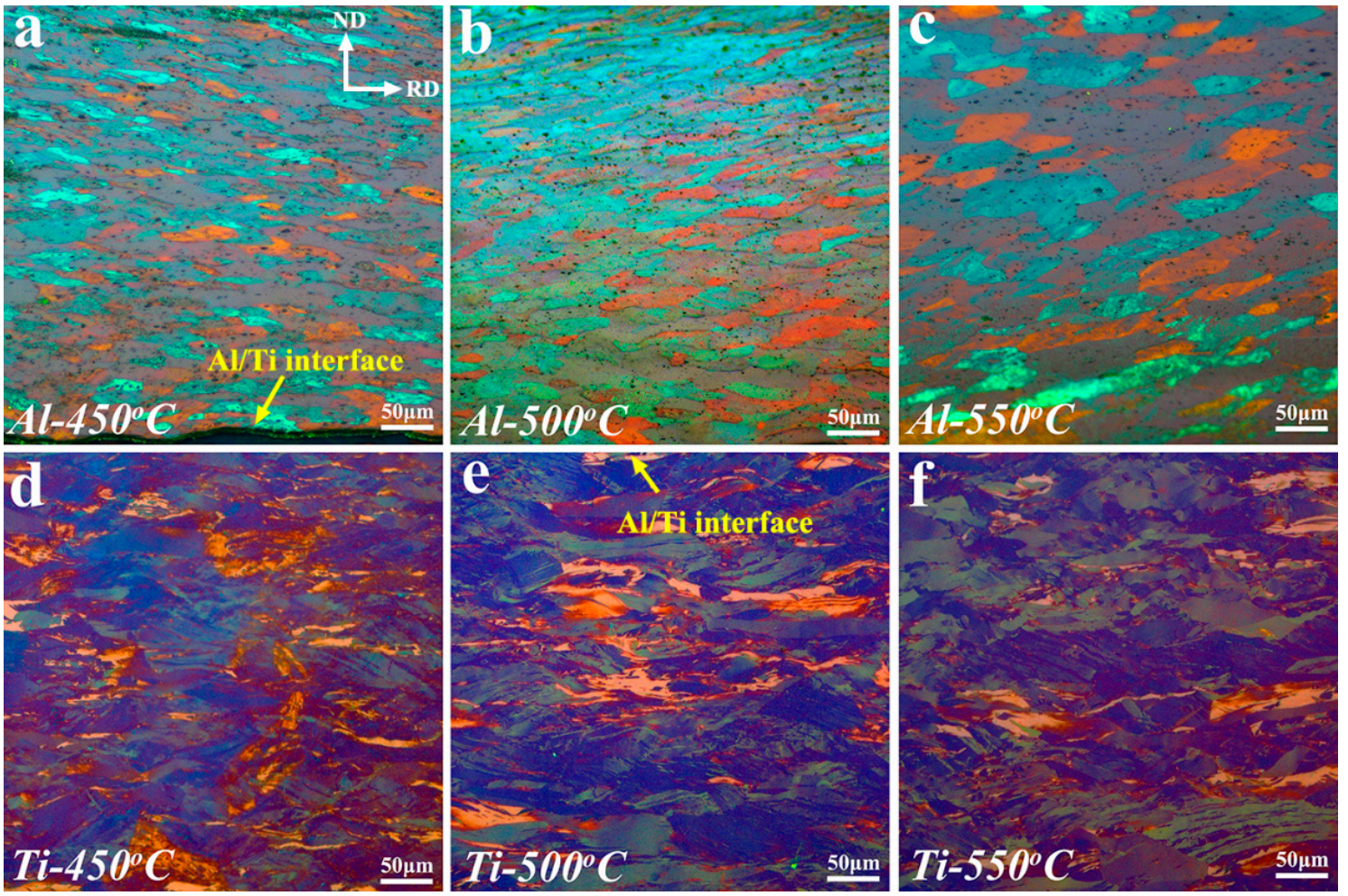

Figure 5. OM micrographs of $\mathrm{Al}$ layer and Ti layer of LMCs undergoing pre-rolling diffusion process:

(a,d) diffused at $450{ }^{\circ} \mathrm{C} ;(\mathbf{b}, \mathbf{e})$ diffused at $500{ }^{\circ} \mathrm{C} ;(\mathbf{c}, \mathbf{f})$ diffused at $550{ }^{\circ} \mathrm{C}$.

From Figure $5 \mathrm{a}-\mathrm{c}$, it can be seen that the grains of $\mathrm{Al}$ layer were obviously elongated along the rolling direction. The grain sizes near the interface are greatly larger than the grain size far from the interface, revealing that the effect of uncoordinated deformation between constituent layers and the friction between roller and surface of Al layer. In addition, the increasing of grain size with increasing diffusion temperature was also observed in Al layers, which is attributed to the recovery and recrystallization occurred in the Al layers when the LMCs were subjected to diffusion at different temperature for $1 \mathrm{~h}$. The similar evolution trend can be detected during annealing process of rolled LMCs $[19,20]$. On the other hand, detailed inspection in Figure $5 d-f$ reveals, after pre-rolling diffusion process, the increasing of deformed microstructure can be detected and initial grains of pure Ti were developed into the lamellar microstructure, which resulted from the cold rolling process before diffusion. However, with increase of diffusion temperature, the grains of Ti layer still remained deformed structure without significant recovery and recrystallization, which is due to the diffusion temperature from 450 to $550^{\circ} \mathrm{C}$ is not enough to cause significant recrystallization in Ti layers. Interestingly, a lot of twinning can be found in Ti layers for all diffused samples, indicating that less slip system were activated. As is well known, some typical twinning were developed in Ti during deformation, such as $\{1 \overline{2} 12\}<1 \overline{1} 00>$ compressive twinning and $\{11 \overline{2} 1\}<1 \overline{1} 01>$ or $\{1 \overline{1} 02\}<11 \overline{2} 0>$ tensile twinning, which have become an important way of plastic deformation in pure Ti. Also, the activated deformation twining in Ti during rolling process will lead to further fragmentation of microstructure [23,24].

\subsection{Effect of Pre-Rolling Diffusion on Mechanical Properties of Hot-Rolled Al/Ti LMCs}

The effect of pre-rolling diffusion process on mechanical properties of Al/Ti LMCs was investigated. Table 3 summarizes the maximum shear strength of Al/Ti LMCs obtained from the shear test to evaluate the interfacial bonding ability. 
Table 3. Maximum shear strength of hot-rolled Al/Ti LMCs.

\begin{tabular}{cccc}
\hline Samples & Shear Area $\left(\mathbf{m m}^{\mathbf{2}}\right)$ & Load $(\mathbf{N})$ & Maximum Shear Strength (MPa) \\
\hline Conventional process & 4.13 & 92.36 & 22.36 \\
D450 & 4.13 & 107.3 & 25.98 \\
D500 & 4.07 & 112.8 & 27.72 \\
D550 & 4.00 & 120.24 & 30.06 \\
\hline
\end{tabular}

It can be seen that, when the diffusion temperature was increased to $450{ }^{\circ} \mathrm{C}$, the max shear strength of conventional hot-rolling plate increased from 22.36 to $25.98 \mathrm{MPa}$. With further increasing of temperature, the shear strength was increased gradually for all pre-rolling process samples. It is interesting to note that the most excellent bonding strength was detected at $550{ }^{\circ} \mathrm{C}$ for $1 \mathrm{~h}$ sample (30.06 MPa), which is much higher than the conventional sample. The improvement of bonding strength can be explained by the optimized bonding interface. In present study, the pre-rolling diffusion promoted the formation of IMCs $\mathrm{TiAl}_{3}$ in bonding interface, resulting in the oxides or other inclusions were restricted and excellent bonding was achieved. That is to say, the bonding interface was improved obviously over the conventional sheets. On the other hand, the IMCs $\mathrm{TiAl}_{3}$ acted as a reinforcement phase in the interface and restricted the movement of dislocation, which could be a reason for the bonding strength was reinforced. For the pre-rolling diffusion process, the max shear strength of $\mathrm{Al} / \mathrm{Ti}$ LMCs increased from 25.98 to $30.06 \mathrm{MPa}$ when the diffusion temperature was increased from 450 to $550{ }^{\circ} \mathrm{C}$, which is attributed to the development of diffusion layer. As shown in the EDS results (Figure $3 \mathrm{~d}, \mathrm{f}$ ), when the diffusion temperature was increased from 450 to $550{ }^{\circ} \mathrm{C}$, the thickness in diffusion layer was increased from 1.65 to $3.72 \mu \mathrm{m}$, indicating that the thickness in diffusion layer plays an important role on the improvement of interfacial structure.

Investigating the bonding ability on the interface in the Al/Ti LMCs required further analyzing the micro-morphology for bonding interface after shear test. Figure 6 shows the shear surface of the $\mathrm{Al} / \mathrm{Ti}$ LMCs under the conditions of conventional process and D550 (red represents aluminum and green represents titanium).
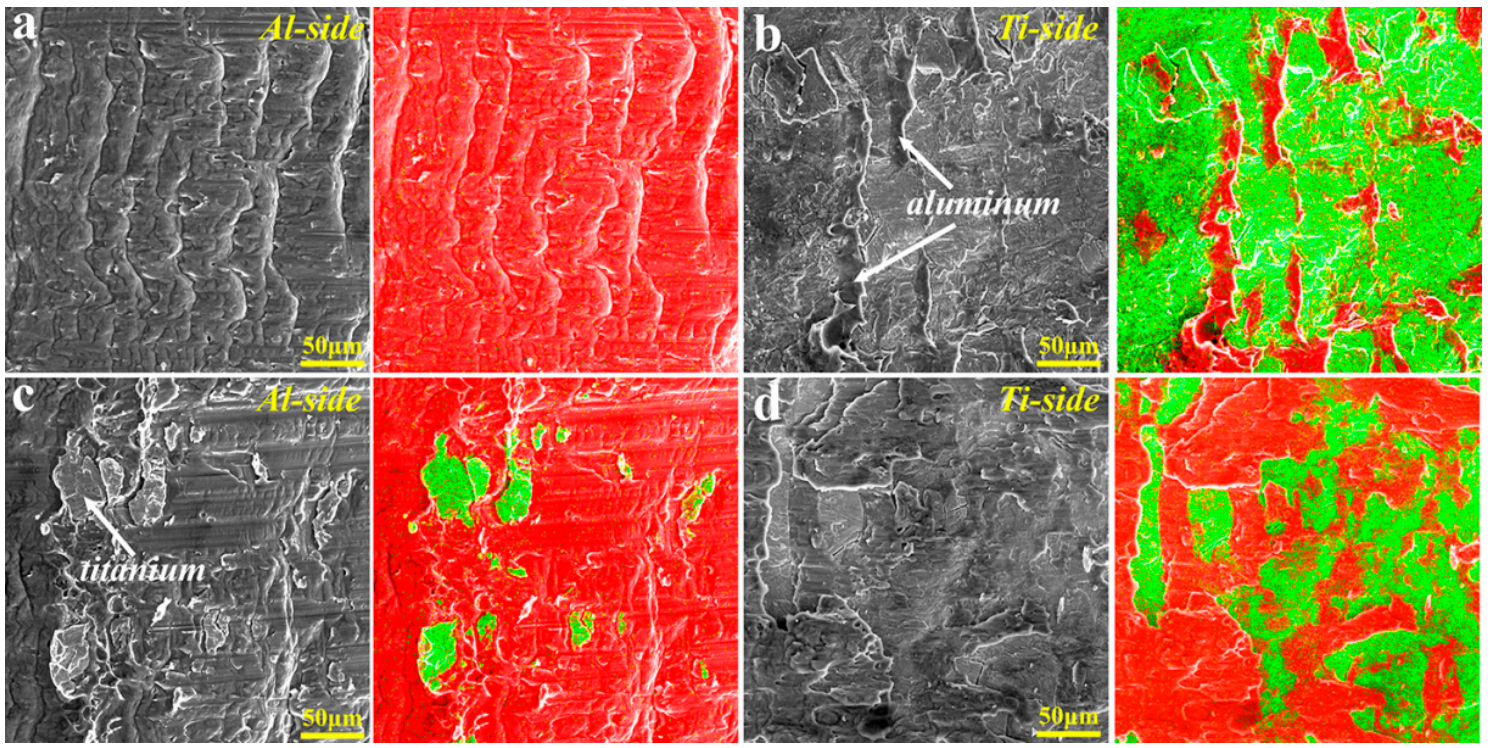

Figure 6. SEM images of the shear surfaces of the Al/Ti LMCs under the conditions of the conventional process $(\mathbf{a}, \mathbf{b})$ and D550 process $(\mathbf{c}, \mathbf{d})$.

As shown in Figure 6a, tearing morphology can be observed in the Al side of conventional processed sample, and no titanium is found on the shear surface. Besides, Figure $6 \mathrm{~b}$ presents the sporadic aluminum is stuck on the Ti side. Compared with conventional processed sample, fracture 
surface of the hot-rolled sample fabricated by pre-rolling diffusion at $550{ }^{\circ} \mathrm{C}(\mathrm{D} 550)$ exhibited a small number of titanium stuck in Al side. More obviously, as the image of the Ti side of the D550 shown in Figure $6 \mathrm{~d}$, considerable fraction of aluminum stuck on the Ti side, rather than rare as the conventional processed sample, indicating the optimization of bonding ability for interface after pre-rolling diffusion.

The tensile specimens were cut into the size shown in Figure 2a to execute the tensile tests, and the stress-strain curves of LMCs fabricated by hot rolling were obtained as Figure 7.

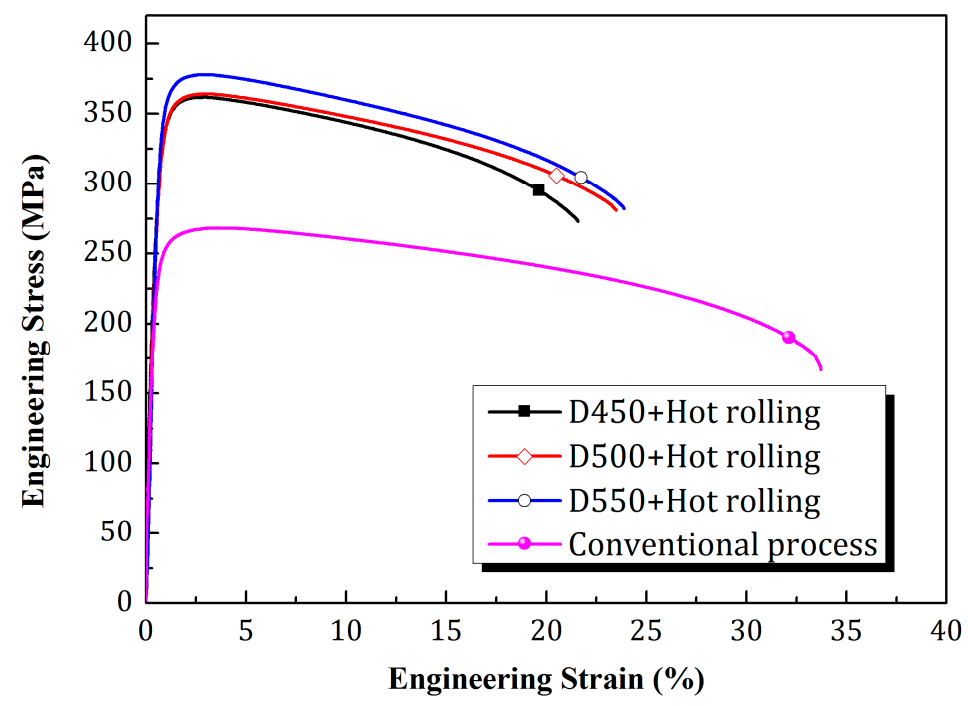

Figure 7. Engineering stress-strain curve of Al/Ti LMCs after hot rolling.

It can be seen from Figure 7 that the tensile strengths of Al/Ti LMCs optimized by pre-rolling diffusion process were also obviously higher than conventional sheets. This reveals the pre-rolling diffusion process provided by present investigation has a positive effect on the mechanical properties of $\mathrm{Al} / \mathrm{Ti} \mathrm{LMCs}$. In addition, for the samples fabricated by pre-rolling diffusion process, the tensile strength of $\mathrm{Al} / \mathrm{Ti} \mathrm{LMCs}$ was increased with increasing of diffusion temperature, which is consistent with the development trend of bonding strength in Table 3. With increasing diffusion temperature, the optimized interfacial structure resulted in the improvement of bonding strength of Al/Ti LMCs. For the LMC materials, it can be believed that the development of interfacial bonding ability has a significant effect on the fracture behavior, thus affects the mechanical properties [9]. On the other hand, the total elongation of $\mathrm{Al} / \mathrm{Ti} \mathrm{LMCs}$ exhibits an increasing trend with diffusion temperature from 450 to $550{ }^{\circ} \mathrm{C}$ but lower than the conventional sheets. The main reason for the decreasing of ductility for pre-rolling diffusion processed samples is explainable by the effect of work hardening on Al/Ti LMCs in the cold rolling stage.

The tensile fracture morphologies of hot-rolled $\mathrm{Al} / \mathrm{Ti} \mathrm{LMCs}$ at different diffusion temperature were presented in Figure 8. It is obvious that ductility fracture was the main characteristic of $\mathrm{Al}$ and Ti constituent layers. With increasing diffusion temperature, the predominant mechanism of Al layers can be determined by increasing dimple size. In contrast, the dimple size in the fracture surface of Ti layers almost remained same for all hot-rolled LMCs fabricated by diffusion. In addition, it can be observed that, the gradient distribution of microstructure can be detected in the fracture surface through the thickness of Al layers. This inhomogeneity of the microstructure can be explainable for the effect of the friction between the sheet and roller and the uncoordinated deformation between $\mathrm{Al}$ and Ti layers. On the other hand, it is interesting to note that the difference in layer interface can be observed in the fracture surface with increasing diffusion temperature. For the D450 sample, the micrograph of fracture surface (Figure 8a) shows debonding of the layer interface, indicating the weaker bonding strength during tensile test. However, with increasing temperature, an excellent bonding was achieved in D500 and D550 samples, which was attributed to the thickness in $\mathrm{TiAl}_{3} \mathrm{IMCs}$ was increased after pre-rolling diffusion process, as shown in Figure 3. 

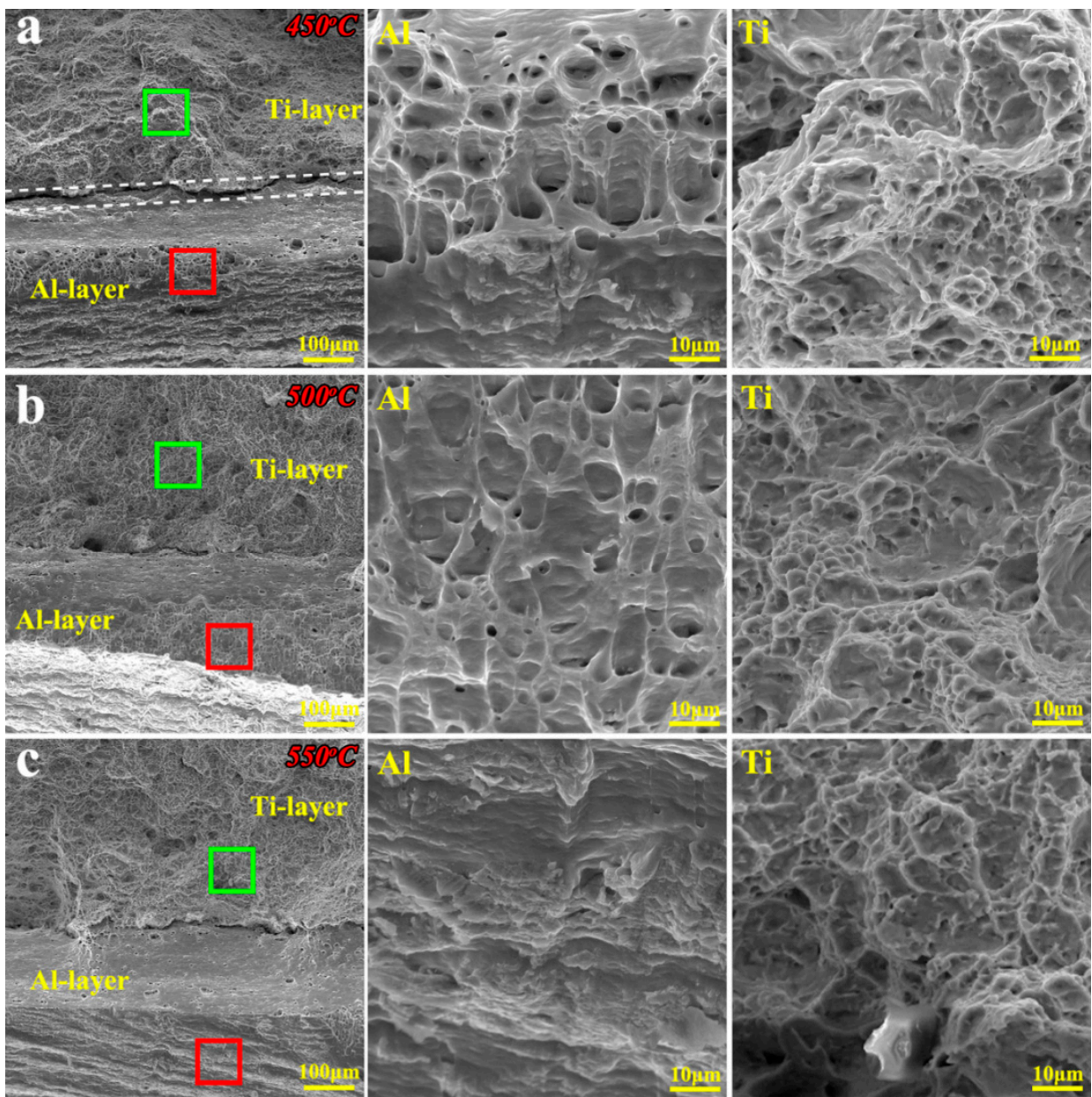

Figure 8. Fracture morphologies of hot-rolled $\mathrm{Al} / \mathrm{Ti} \mathrm{LMCs}$ at different diffusion temperatures: (a) 450 ${ }^{\circ} \mathrm{C}$, (b) $500{ }^{\circ} \mathrm{C}$ and (c) $550{ }^{\circ} \mathrm{C}$. Right images are the magnification of selected zone in left images observed in $\mathrm{Al}$ and Ti layers, respectively.

\subsection{Effect of Annealing on Mechanical Properties of Al/Ti LMCS}

In order to emphasize the improvement of mechanical properties after pre-rolling diffusion, the hot-rolled $\mathrm{Al} / \mathrm{Ti} \mathrm{LMCs}$ were annealed to eliminate residual stress caused by deformation. Figure 9 shows the engineering stress-strain curves of the hot-rolled Al/Ti LMCs after annealing at $550{ }^{\circ} \mathrm{C}$ for $1 \mathrm{~h}$.

It can be seen that the ultimate tensile strength (UTS) of all pre-rolling diffusion processed samples are prominently high compared to the conventional sample. The experimental results after annealing treatment demonstrated that, beside the increased strength provided by the pile-up of dislocation and residual stress after pre-rolling, there existed other factors to affect the mechanical properties. More interestingly, for the mechanical properties after hot rolling (Figure 7), the excellent UTS is obtained in pre-rolling diffusion processed samples while higher elongation can be observed in conventional processed sample. However, after the annealing treatment, the UTS of D550 is still higher than other sample (270 MPa) and its elongation (44.4\%) is higher than that of the conventional hot-rolled sample $(41.7 \%)$. It can be concluded that the improved strength was attributed to the optimization of interfacial structure caused by pre-rolling diffusion process, i.e., increasing of thickness in LMCs. 


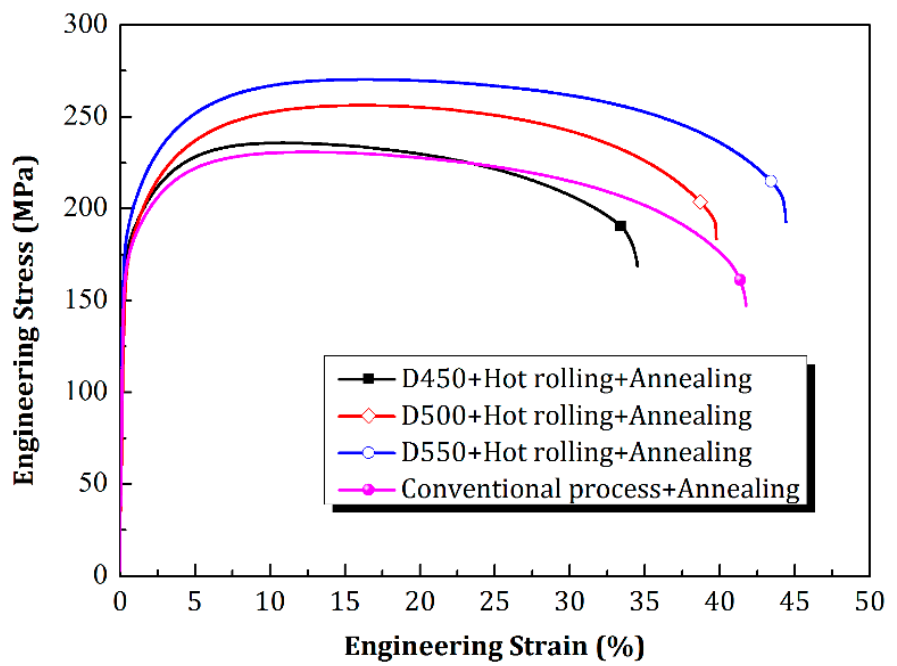

Figure 9. Engineering stress-strain curves of hot-rolled Al/Ti LMCs after annealing treatment.

Figure 10 presents the fracture surface of $\mathrm{Al} / \mathrm{Ti} \mathrm{LMC}$ under the conditions of conventional process and D550 after annealing treatment.

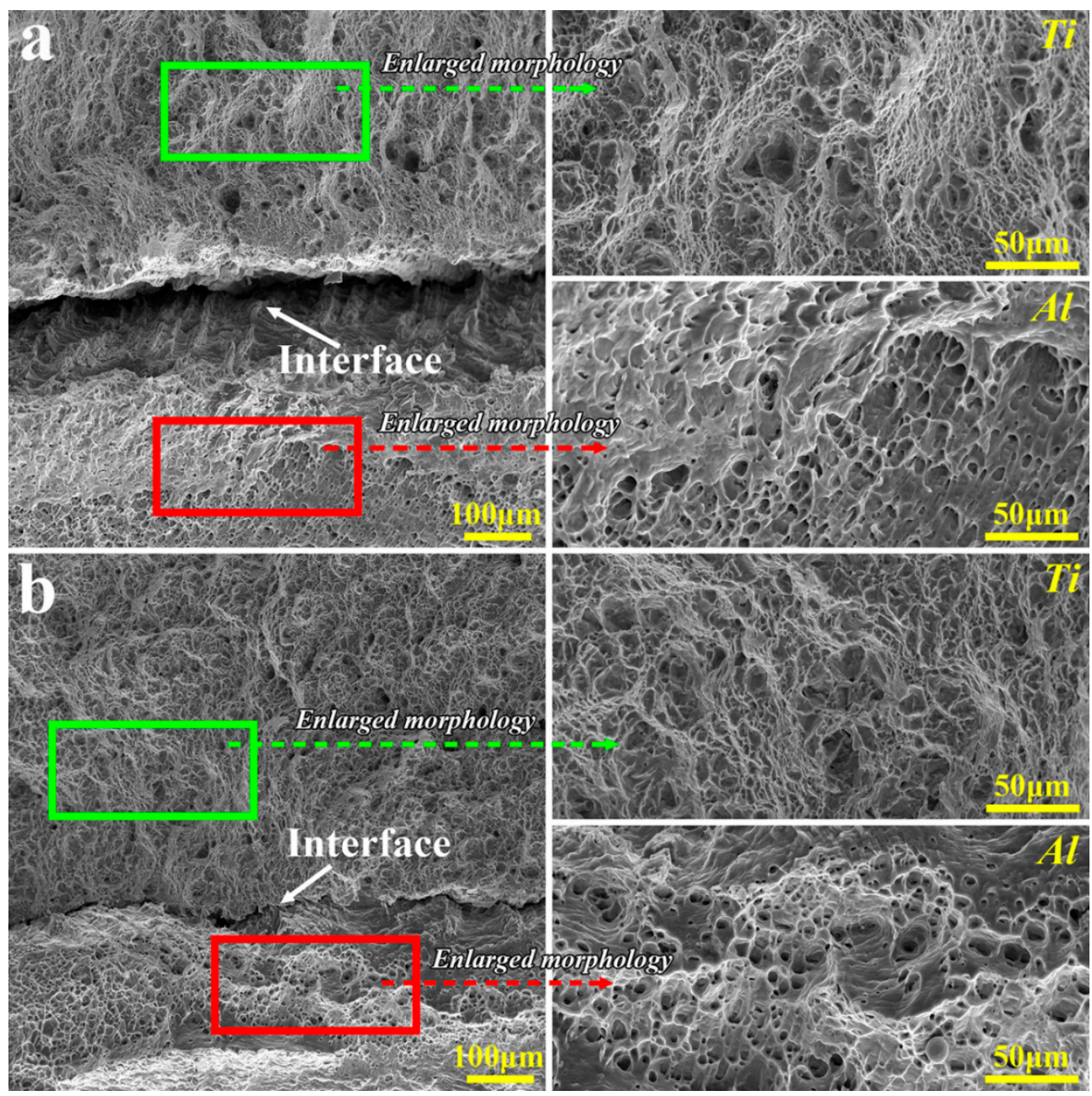

Figure 10. Fracture surfaces of annealed Al/Ti LMCs under the conditions of (a) conventional process and (b) D550. Right images are the magnification of selected zone in left images observed in $\mathrm{Al}$ and $\mathrm{Ti}$ layers, respectively. 
As shown in Figure 10a, the interfacial debonding of layer interface can be recognized after tensile test, and the fracture surfaces of $\mathrm{Al}$ and Ti constituent layers shows obvious sign of plastic fracture. It is interesting to note that similar fracture morphology was detected in D550 sample (Figure 10b). However, an excellent bonding was obtained from the pre-rolling diffusion process, which is closely related to the optimized interface structure. Therefore, it can be believed that increasing bonding quality will lead to the improvement of mechanical properties of Al/Ti LMCs, as observed results in Figure 9.

It is necessary to investigate the effect of interfacial optimization on mechanical properties. The extra strengthening effect provided by layer interface can be predicted by rule of mixture (ROM). For LMCs, the volume fraction-based ROM can be expressed as [25]:

$$
\sigma=V_{\mathrm{Al}} \sigma_{\mathrm{Al}}+V_{\mathrm{Ti}} \cdot \sigma_{\mathrm{Ti}}
$$

where $V_{\mathrm{Al}}, V_{\mathrm{Ti}}, \sigma_{\mathrm{Al}}$ and $\sigma_{\mathrm{Ti}}$ are the volume fraction and the flow stress of relevant $\mathrm{Al}$ and Ti layers in the $\mathrm{Al} / \mathrm{Ti} \mathrm{LMC}$, respectively. Considering the thickness of raw materials, volume fraction of $60 \%$ and $40 \%$ for $\mathrm{Al}$ and $\mathrm{Ti}$ layers were used to ROM calculation.

Figure 11 shows the ultimate tensile strength (UTS) of Al/Ti LMCs and the predicted strength based on the ROM.

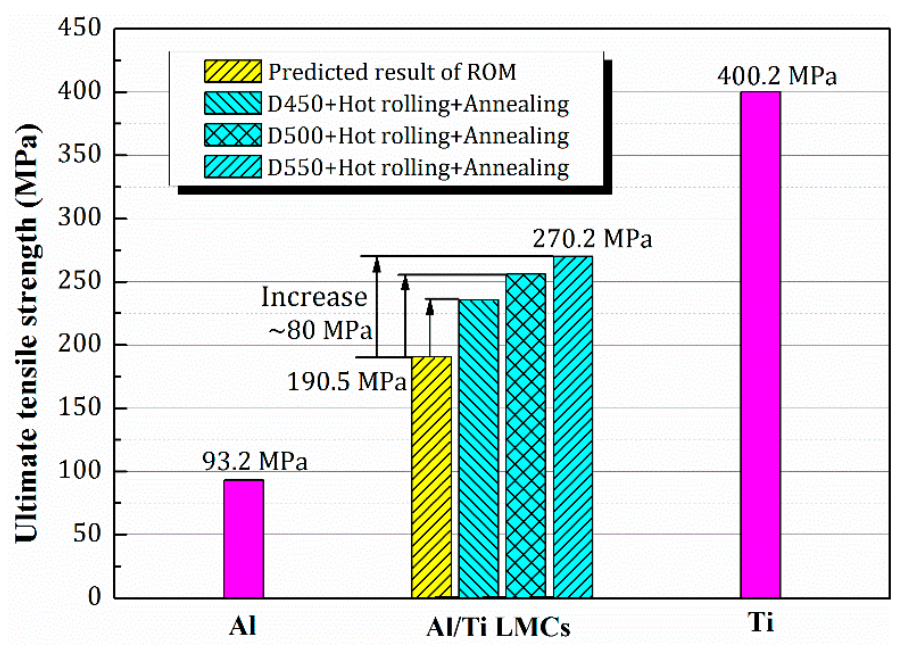

Figure 11. Comparison of the ultimate tensile strength (UTS) of Al/Ti LMCs and the predicted strength based on the ROM (rule of mixture).

As shown in Figure 11, for the pre-rolling diffusion processed samples, it is cleared that the predicted value of UTS from ROM is lower than the experimental observation. An obvious deviation was observed in these samples, indicating that there existed other strengthening mechanisms affected the mechanical properties. In present investigation, the $\mathrm{Al} / \mathrm{Ti} \mathrm{LMCs}$ prepared by pre-rolling diffusion and subsequent hot rolling and annealing process resulted in the formation of $\mathrm{TiAl}_{3} \mathrm{IMCs}_{\text {within }}$ the interface, which played an important role on the improvement of interfacial structure (i.e., inhibition of oxide). That is to say, the improvement of interfacial optimization is a main reason for the formation of extra interface strengthening effect, which improves the mechanical properties of Al/Ti LMCs.

Figure 12 shows the comparison of ultimate tensile strength and total elongation obtained from present experiment and previous references $[10,20,26,27]$. It can be seen that the combination of strength and ductility in present study is excellent to other reported results (Figure 12). The mechanical properties of hot rolled and annealed Al/Ti LMCs were higher than reported references. This indicates that the pre-rolling diffusion process has a positive effect on the mechanical properties of $\mathrm{Al} / \mathrm{Ti} \mathrm{LMCs}$, and has promising potential to produce bulk LMCs for industrial application. 


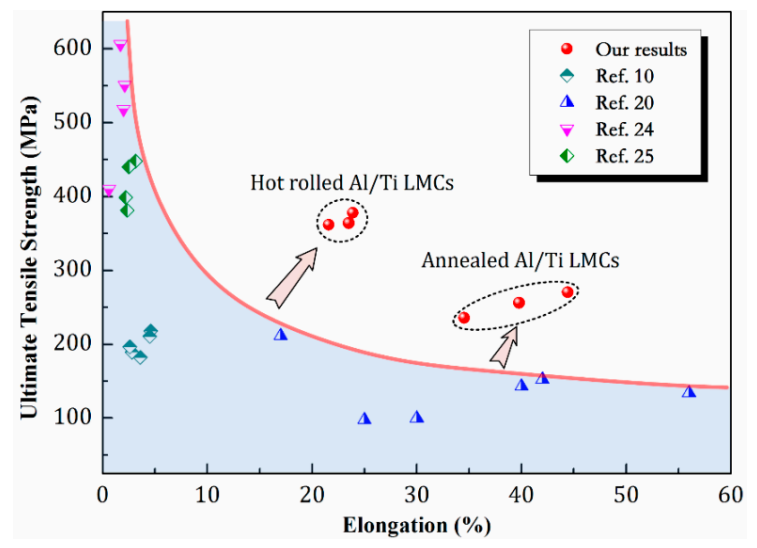

Figure 12. Comparison of ultimate tensile strength and total elongation of Al/Ti LMCs combination between the present investigation and previous references.

\section{Conclusions}

In the present work, $\mathrm{Al} / \mathrm{Ti}$ laminated metal composites (LMCs) were fabricated by introducing a novel pre-rolling diffusion process. The microstructure and mechanical properties of the LMCs at different processes were evaluated and compared. The conclusions can be summarized as follows:

(1) With increasing diffusion temperature, the thickness in diffusion layer comprising the diffusion intermetallic compounds (IMCs) was increased gradually at the bonding interface, resulting in the oxide was inhibited and the bonding strength was improved.

(2) The development of microstructure in Al layers was observed from elongated grain to equiaxed grain with increasing diffusion temperature, while the microstructure of Ti layers was found to be a constant. The inhomogeneity of microstructure through the thickness of Al layer can be attributed to the effect of the friction between the roll and sheet surface and the uncoordinated between constituent layers.

(3) The extra strengthening effect was revealed using rule of mixture (ROM) in the pre-rolling diffusion processed Al/Ti LMCs, which indicated that the interfacial optimization played an important role on the improvement of mechanical properties.

Author Contributions: The individual contributions of authors are as follows, conceptualization, Z.C. and T.M.; methodology, C.Z., S.W. and H.Q.; investigation, C.Z., S.W. and H.Q.; writing-original draft preparation, C.Z., S.W. and H.Q.; writing-review and editing, Z.C. and T.M.; supervision, Z.C. and T.M.; project administration, Z.C., T.M. and Q.L.; funding acquisition, Z.C. and Q.L.

Funding: The authors gratefully acknowledge the support of the National Natural Science Foundation of China (No. 51421001), and Fundamental Research Funds for the Central Universities, grant number (Nos. 2019CDQYCL001, 2019CDCGCL204), and Research Project of State Key Laboratory of Vehicle NVH and Safety Technology, grant number (No. NVHSKL-201706).

Conflicts of Interest: The authors declare no conflict of interest.

\section{References}

1. Li, L.; Nagai, K.; Yin, F. Progress in cold roll bonding of metals. Sci. Technol. Adv. Mater. 2008, 9, 023001. [CrossRef] [PubMed]

2. Du, Y.; Fan, G.; Yu, T.; Hansen, N.; Geng, L.; Huang, X. Laminated Ti-Al composites: Processing, structure and strength. Mater. Sci. Eng. A 2016, 673, 572-580. [CrossRef]

3. Altıntas, Y.; Aksöz, S.; Keşlioğlu, K.; Maraşlı, N. Determination of thermodynamic properties of aluminum based binary and ternary alloys. J. Alloy. Compd. 2015, 649, 453-460. [CrossRef] 
4. Guo, X.; Fan, M.; Liu, Z.; Ma, F.; Wang, L.; Jie, T. Explosive cladding and hot pressing of Ti/Al/Ti laminates. Rare Met. Mater. Eng. 2017, 46, 1192-1196.

5. Zhao, H.; Yu, M.; Jiang, Z.; Zhou, L.; Song, X. Interfacial microstructure and mechanical properties of Al/Ti dissimilar joints fabricated via friction stir welding. J. Alloys Compd. 2019, 789, 139-149. [CrossRef]

6. Siddiq, A.; Schmauder, S.; Huang, Y. Fracture of bicrystal metal/ceramic interfaces: A study via the mechanism-based strain gradient crystal plasticity theory. Int. J. Plast. 2007, 23, 665-689. [CrossRef]

7. Shokrani, A.; Dhokia, V.; Newman, S.T. Environmentally conscious machining of difficult-to-machine materials with regard to cutting fluids. Int. J. Mach. Tools Manuf. 2012, 57, 83-101. [CrossRef]

8. Kuemmel, F.; Kreuz, M.; Hausöel, T.; Höeppel, H.W.; Göeken, M. Microstructure and mechanical properties of accumulative roll-bonded AA1050A/AA5005 laminated metal composites. Metals 2016, 6, 56. [CrossRef]

9. Cepeda-Jiménez, C.M.; Pozuelo, M.; Ruano, O.A.; Carreño, F. Influence of the thermomechanical processing on the fracture mechanisms of high strength aluminium/pure aluminium multilayer laminate materials. Mater. Sci. Eng. A 2008, 490, 319-327. [CrossRef]

10. Ma, M.; Huo, P.; Liu, W.C.; Wang, G.J.; Wang, D.M. Microstructure and mechanical properties of Al/Ti/Al LMCs prepared by roll bonding. Mater. Sci. Eng. A 2015, 636, 301-310. [CrossRef]

11. Motevalli, P.D.; Eghbali, B. Microstructure and mechanical properties of Tri-metal Al/Ti/Mg laminated composite processed by accumulative roll bonding. Mater. Sci. Eng. A 2015, 628, 135-142. [CrossRef]

12. Wu, F.; Zhou, W.L.; Zhao, B.; Hou, H.L. Interface microstructure and bond strength of 1420/7B04 composite sheets prepared by diffusion bonding. Rare Met. 2018, 37, 613-620. [CrossRef]

13. Bian, H.; Lei, Y.; Fu, W.; Hu, S.; Song, X.; Feng, J. Diffusion bonding of $\mathrm{Ti}_{2} \mathrm{AlNb}$ alloy and high-Nb-containing TiAl alloy: Interfacial microstructure and mechanical properties. Metals 2018, 8, 1061. [CrossRef]

14. Fronczek, D.M.; Chulist, R.; Litynska-Dobrzynska, L.; Szulc, Z.; Zieba, P.; Wojewoda-Budka, J. Microstructure changes and phase growth occurring at the interface of the $\mathrm{Al} / \mathrm{Ti}$ explosively welded and annealed joints. J. Mater. Eng. Perform. 2016, 25, 3211-3217. [CrossRef]

15. Fronczek, D.M.; Wojewoda-Budka, J.; Chulist, R.; Sypien, A.; Korneva, A.; Szulc, Z.; Schell, N.; Zieba, P. Structural properties of Ti/Al clads manufactured by explosive welding and annealing. Mater. Des. 2016, 91, 80-89. [CrossRef]

16. Fan, M.; Luo, Z.; Fu, Z.; Guo, X.; Jie, T. Vacuum hot pressing and fatigue behaviors of Ti/Al laminate composites. Vacuum 2018, 154, 101-109. [CrossRef]

17. Liang, Q.; Fan, M.; Guo, X.; Jie, T. Plastic deformation behaviors of Ti-Al laminated composite fabricated by vacuum hot-pressing. Vacuum 2018, 155, 96-107.

18. Kong, F.; Chen, Y.; Zhang, D. Interfacial microstructure and shear strength of Ti-6Al-4V/TiAl laminate composite sheet fabricated by hot packed rolling. Mater. Des. 2011, 32, 3167-3172. [CrossRef]

19. Chaudhari, G.P.; Acoff, V.L. Titanium aluminide sheets made using roll bonding and reaction annealing. Intermetallics 2010, 18, 472-478. [CrossRef]

20. Yu, H.; Cheng, L.; Tieu, A.K.; Li, H.; Godbole, A.; Kong, C. Annealing effect on microstructure and mechanical properties of Al/Ti/Al laminate sheets. Mater. Sci. Eng. A 2016, 660, 195-204. [CrossRef]

21. Bataev, I.A.; Bataev, A.A.; Mali, V.I.; Pavliukova, D.V. Structural and mechanical properties of metallic-intermetallic laminate composites produced by explosive welding and annealing. Mater. Des. 2012, 35, 225-234. [CrossRef]

22. Mirjalili, M.; Soltanieh, M.; Matsuura, K.; Ohno, M. On the kinetics of $\mathrm{TiAl}_{3}$ intermetallic layer formation in the titanium and aluminum diffusion couple. Intermetallics 2013, 32, 297-302. [CrossRef]

23. Xu, F.; Zhang, X.; Ni, H.; Cheng, Y.; Zhu, Y.; Liu, Q. Effect of twinning on microstructure and texture evolutions of pure Ti during dynamic plastic deformation. Mater. Sci. Eng. A 2013, 564, 22-33. [CrossRef]

24. Sahoo, S.; Sabat, R.; Sahni, S.; Suwas, S. Texture and microstructure evolution of commercially pure titanium during hot rolling: Role of strain-paths. Mater. Des. 2016, 91, 58-71. [CrossRef]

25. Yang, D.; Cizek, P.; Hodgson, P.; Wen, C.E. Ultrafine equiaxed-grain Ti/Al composite produced by accumulative roll bonding. Scr. Mater. 2010, 62, 321-324. [CrossRef] 
26. Lyu, S.; Sun, Y.; Lei, R.; Xiao, W.; Ma, C. Simultaneously achieving high tensile strength and fracture toughness of Ti/Ti-Al multilayered composites. Intermetallics 2017, 90, 16-22. [CrossRef]

27. Gang, C.; Song, X.; Nan, H.; Wang, H.; Tian, Y. Effect of initial Ti powders size on the microstructures and mechanical properties of $\mathrm{Al}_{3} \mathrm{Ti} / 2024 \mathrm{Al}$ composites prepared by ultrasonic assisted in-situ casting. J. Alloys Compd. 2017, 694, 539-548. 